\title{
Acid stress adaptation protects Saccharomyces cerevisiae from acetic acid-induced programmed cell death
}

\author{
Sergio Giannattasio ${ }^{\mathrm{a}, *, 1}$, Nicoletta Guaragnella ${ }^{\mathrm{a}, 1}$, Manuela Corte-Real ${ }^{\mathrm{b}}$, \\ Salvatore Passarella ${ }^{c}$, Ersilia Marra ${ }^{a}$ \\ ${ }^{\mathrm{a}}$ Istituto di Biomembrane e Bioenergetica, Consiglio Nazionale delle Ricerche, Bari, Italy \\ ${ }^{\mathrm{b}}$ Department of Biology, School of Sciences, University of Minho, Braga, Portugal \\ ${ }^{\mathrm{c}}$ Dipartimento di Scienze per la Salute, Università del Molise, Campobasso, Italy
}

Received 14 December 2004; accepted 23 March 2005

Available online 13 May 2005

Received by K. Wolf

\begin{abstract}
In this work evidence is presented that acid stress adaptation protects Saccharomyces cerevisiae from acetic acid-mediated programmed cell death. Exponential-phase yeast cells, non-adapted or adapted to acid stress by 30 min incubation in rich medium set at pH $3.0 \mathrm{with} \mathrm{HCl}$, have been exposed to increasing concentrations of acetic acid and time course changes of cell viability have been assessed. Adapted cells, in contrast to non-adapted cells, when exposed to $80 \mathrm{mM}$ acetic acid for $200 \mathrm{~min}$ did not display loss of cell viability associated to morphological alterations typical of apoptosis. Thus, $80 \mathrm{mM}$ acetic acid death-inducing conditions were selected to further characterize the early molecular events leading to such active cell death process. Catalase was specifically activated during acid stress adaptation and protection against acetic acid-induced death was associated with maintenance of its activity during treatment with $80 \mathrm{mM}$ acetic acid. On the other hand, intracellular superoxide dismutase activity was found present at comparable levels both in adapted and in dying yeast cells, excepting in non-adapted cells which displayed a maximum activity value after 15 min acetic acid exposure, corresponding to more than $80 \%$ cell viability.

This study gives first experimental evidence that $\mathrm{H}_{2} \mathrm{O}_{2}$, rather than superoxide, detoxification may have a major role in preventing yeast cell death in response to acetic acid. The results, as a whole, suggest that commitment of $S$. cerevisiae to a programmed cell death process in response to acetic acid is mediated through a ROS-dependent apoptotic pathway.
\end{abstract}

(C) 2005 Elsevier B.V. All rights reserved.

Keywords: Saccharomyces cerevisiae; Programmed cell death; Strong acid stress; Superoxide dismutase; Catalase

Abbreviations: DAPI, 4',6-diamidino-2-phenylindole; mtDNA, mitochondrial DNA; PCD, programmed cell death; ROS, reactive oxygen species; SOD, superoxide dismutase; TUNEL, terminal deoxynucleotidyl transferase dUTP nick-end labelling.

* Corresponding author. Consiglio Nazionale delle Ricerche, Istituto di Biomembrane e Bioenergetica, Via Amendola 165/A, I-70126, Bari, Italy. Tel.: +39 0805443316; fax: +390805443317.

E-mail address: s.giannattasio@ibbe.cnr.it (S. Giannattasio).

${ }^{1}$ Contributed equally to this paper.

\section{Introduction}

Different metazoan cell types undergo a kind of death program termed apoptosis in response to environmental insults or specific exogenous or endogenous signals for tissue maintenance and/or organism homeostasis (Adams, 2003). Although the physiological significance of programmed cell death in yeast (Skulachev, 1999; 2002) is still controversial, programmed cell death has been reported so far from prokaryotes (Lewis, 2000) to unicellular eukaryotes (Ameisen, 1996). Apoptotic death is genetically determined and apoptotic cells are characterized by a 
specific series of morphological and biochemical properties which are distinct from the features observed in cells undergoing accidental death or necrosis (Wyllie et al., 1980; Hengartner, 2000).

Regulatory pathways and inducers vary depending on tissue, developmental state and host organism, resulting in diverse and sometimes contradictory models for the regulation of apoptosis in higher eukaryotes. A lower eukaryotic organism such as yeast seems to be a suitable model to identify components of the basic, evolutionarily ancient stages of apoptosis. Moreover, in the budding yeast Saccharomyces cerevisiae, mtDNA is dispensable for growth as long as cells are supplied with a fermentable carbon source. In view of the pivotal and not yet fully elucidated role of mitochondria in apoptosis (Wang, 2001; Newmeyer and Ferguson-Miller, 2003), yeast provides a convenient experimental system for analyzing how cells respond to changes in the functional state of mitochondria (Butow and Avadhani, 2004).

Notwithstanding the apparent absence in yeasts of genes encoding the metazoan apoptotic machinery, various experimental evidences have been recently collected claiming that yeast undergo apoptosis (Madeo et al., 2004). In addition, recent exploitation of yeast as tools for studying human and animal apoptosis-regulatory proteins has yielded novel insights into cell death mechanisms and created opportunities for genetic screens (Matsuyama et al., 1999).

Weak acids are potent fungistatic agents used in food preservation and certain yeast strains have attracted attention as spoilage agents of wine fermentation. In $S$. cerevisiae cell growth is frequently inhibited by weak acids such as acetic acid produced by its normal fermentation as well as by competitor microbes. To counteract weak acid effects yeast is endowed with a stress response that acts to reduce the possibility that weak acids will accumulate within its cells to high, potentially toxic, levels (Piper et al., 2001; Schuller et al., 2004). In this context it has been shown that acetic acid (20-80 mM) induces death in exponential cells of $S$. cerevisiae strain W303-1A displaying certain common PCD hallmarks such as chromatin condensation along the nuclear envelope, exposure of phosphatidylserine on the outer surface of the plasma membrane, and occurrence of TUNEL-positive phenotype (Ludovico et al., 2001). A mitochondria-dependent pathway have also been implicated in death induced by acetic acid in the same yeast strain cells grown up to stationary phase (Ludovico et al., 2002). In yeast cells undergoing apoptosis under such conditions translocation of cytochrome $\mathrm{c}$ to the cytosol and ROS production was observed.

In view of the physiological and biotechnological relevance of acetic acid-triggered yeast cell death, it seemed worthwhile to further investigate the mechanisms underlying this cell death mode in yeast. Moreover, in order to address whether reactive oxygen species are mediators or just by-products of such death process, antioxidant enzyme activities were assessed both in adaptation conditions that protected yeast cell from acetic acid-induced programmed cell death, as well as in non-adapted and adapted cells during treatment with acetic acid.

\section{Materials and methods}

\subsection{Strain and growth conditions}

The $S$. cerevisiae strain used in this study was W303-1B (MAT $\alpha$ ade2 leu2 his3 trp1 ura3). Cells were grown at 26 ${ }^{\circ} \mathrm{C}$ in rich medium (1\% yeast extract and $2 \%$ Bacto-peptone) containing $2 \%$ dextrose (YPD).

\subsection{Acetic acid treatment}

Cells were grown up to exponential phase $\left(\mathrm{OD}_{600}=0.7-\right.$ $0.8)$ in YPD medium, resuspended $\left(10^{7}\right.$ cells $\left./ \mathrm{ml}\right)$ in YPD medium adjusted to $\mathrm{pH} 3.0$ with $\mathrm{HCl}$ and containing different concentrations of acetic acid and incubated for different times at $26{ }^{\circ} \mathrm{C}$ as described in Ludovico et al. (2001). Cell viability was determined by measuring colonyforming units (cfu) after 2 days of growth on YPD plates at $26{ }^{\circ} \mathrm{C}$. Adapted cells were maintained in YPD pH 3.0 medium for $30 \mathrm{~min}$ before addition of acetic acid. Control cells were grown in YPD pH 3.0 medium without acetic acid.

\subsection{Catalase and superoxide dismutase activity assay}

Exponentially grown cells $\left(10^{8}\right)$, directly exposed to acetic acid or pretreated in acidic medium before the exposure, were sedimented by centrifugation, washed once with $50 \mathrm{mM}$ potassium phosphate buffer $\mathrm{pH} 7.0$ for catalase assay or with $50 \mathrm{mM}$ potassium phosphate buffer $\mathrm{pH} 7.8$ for superoxide dismutase assay, resuspended in $0.3 \mathrm{ml}$ of the same buffer, respectively. Cells were broken with $1 / 3$ volume of ice-chilled glass beads $(0.5 \mathrm{~mm}$ BioSpec Products, Bartesville, OK, USA) by vortexing four times for $1 \mathrm{~min}$ with $1 \mathrm{~min}$ intervals in an ice bath and centrifuged for $10 \mathrm{~min}$ centrifugation $(15,000 \times \mathrm{g})$ to clarify the supernatant. A $20-60 \mu 1$ supernatant was used for enzyme assay. All reagents used for catalytic activity measurements were from Sigma (St. Louis, MO, USA). Total catalase activity was measured spectrophotometrically by monitoring the disappearance of hydrogen peroxide at $240 \mathrm{~nm}$ (Luck, 1954). One unit of enzyme activity corresponded to the decomposition of $1 \mu \mathrm{mol}$ substrate in $1 \mathrm{~min}$. SOD activity was assayed spectrophotometrically by following the rate of reduction of ferri-cytochrome $\mathrm{c}$ at $550 \mathrm{~nm}$ in the presence of xanthine and xanthine oxidase as the source of superoxide anion (Flohe and Otting, 1984). In this assay, SOD competes with ferri-cytochrome $\mathrm{c}$ for superoxide oxidation. SOD activity is expressed as percentage of inhibition of ferri-cytochrome c reduction rate. Protein concentration was determined using the Bio Rad protein assay (Bio Rad 
Laboratories, Hercules, CA), with bovine serum albumin as a standard.

\section{Results}

\subsection{S. cerevisiae W303-1B acetic acid-mediated cell death process is dependent on weak acid dosage and is prevented by culture medium pre-acidification}

Exponentially growing $S$. cerevisiae W303-1B cells have been exposed to increasing concentration $(0-240 \mathrm{mM})$ of acetic acid in YPD pH 3.0 medium. Cell viability was estimated by assaying the ability to sustain colonial growth through measurement of colony-forming units (cfu) on rich medium 60, 90, 150 and 200 min after acetic acid addition (Fig. 1). Yeast cell viability increased to $180 \%$ during 200 min growth in $\mathrm{pH} 3.0$ medium whereas 40 and $60 \mathrm{mM}$ acetic acid were shown to have an inhibitory but not toxic effect on cell growth. The minimum acetic acid concentration at which cells die was $80 \mathrm{mM}$. For this acid concentration cell viability was $60 \%$ after 60 min acetic acid treatment, decreased to $30 \%$ at 90 min and virtually all cells were unviable after $200 \mathrm{~min}$. At acetic acid concentration of $140 \mathrm{mM}$ and greater, the death process was already complete $60 \mathrm{~min}$ after acetic acid challenge. The kinetics of the death process induced by $80 \mathrm{mM}$ acetic acid seems suitable for further characterization of the early molecular events leading to cell death. Moreover, according to previous observations (Ludovico et al., 2001) showing that $S$. cerevisiae W303-1A commits to a programmed cell death process in response to $20-80 \mathrm{mM}$ acetic acid exposure, fluorescence microscopy analysis of the opposite mating type strain $S$. cerevisiae W303-1B cells, after 60 min treatment with $80 \mathrm{mM}$ acetic acid, showed abnormal nuclear

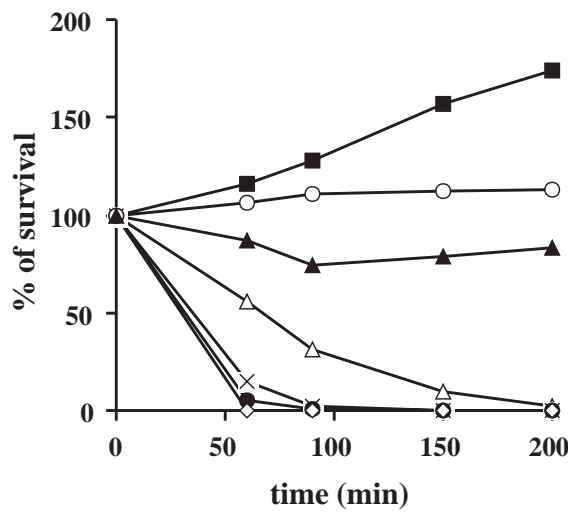

Fig. 1. Viability of exponentially growing S. cerevisiae W303-1B cells exposed to acetic acid. Cells $\left(10^{7}\right.$ cells $\left./ \mathrm{ml}\right)$, grown in YPD medium $\mathrm{pH}$ 7.0 up to $\mathrm{OD}_{600}=0.7-0.8$ (exponential phase), were harvested and exposed to $0(\mathbf{\square}), 40(\bigcirc), 60(\mathbf{\Delta}), 80(\triangle), 140(\times), 180(\bullet)$ and $240 \mathrm{mM}$ $(\diamond)$ acetic acid in YPD medium $\mathrm{pH}$ 3.0. At indicated times, cell viability was analyzed by measuring colony-forming units (cfu) after 2 days of growth on YPD pH 7.0 plates at $26^{\circ} \mathrm{C}$. Cell survival $(100 \%)$ corresponds to the cfu at time zero.

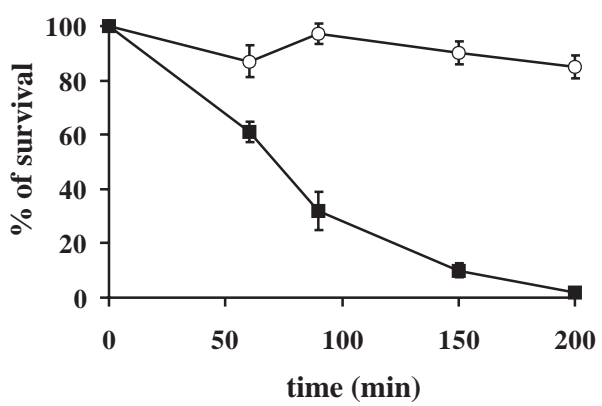

Fig. 2. Effect of low pH medium pre-treatment on cell death induced by acetic acid exposure. Exponential-phase yeast cells $\left(10^{7}\right.$ cells $\left./ \mathrm{ml}\right)$ were exposed to acetic acid $80 \mathrm{mM}$ in YPD medium $\mathrm{pH} 3.0$ with $(\mathrm{O})$ or without ( $\square$ ) pre-treatment in acidic medium for $30 \mathrm{~min}$. At indicated times, cell viability was analyzed by cfu counting. Cell survival (100\%) corresponds to the cfu at time zero.

morphology indicative of chromatin condensation and intact plasma membrane as judged by DAPI/propidium iodide double staining (data not shown). Thus, $80 \mathrm{mM}$ acetic acid concentration was selected to further investigate acetic acidmediated yeast programmed cell death.

With the aim of identifying major molecular steps in the commitment and execution phase of acetic acid-triggered yeast cell death, we tried to induce an adaptive response which could protect yeast cells from demise after acetic acid challenge. It is well-known that pre-treatment with one kind of stressing agent may induce cross-resistance against another type of stress agent in yeast (Evans et al., 1998). Thus, exponentially growing W303-1B cells were preincubated in YPD medium $\mathrm{pH}$ 3.0, 30 min prior to exposure to $80 \mathrm{mM}$ acetic acid. Virtually all cells pre-incubated in YPD pH 3.0 for $30 \mathrm{~min}$ remained viable after $200 \mathrm{~min} 80$ $\mathrm{mM}$ acetic acid treatment (Fig. 2). This protective effect was already complete after 20 min medium pre-acidification, whereas after 10 min pre-incubation in YPD pH 3.0 only $53 \%$ cells survived after death induction (Fig. 3A). When cells were grown up to mid-log phase in YPD pH 7.0 and subsequently pre-incubated for $30 \mathrm{~min}$ in fresh YPD medium $\mathrm{pH} 7.0$ before acetic acid treatment, they were not protected from death (data not shown), thus showing the specificity of pre-exposure to acidic extracellular medium in preventing acetic acid-triggered cell death.

Exponential-phase W303-1B cells were incubated for 30 min in YPD $\mathrm{pH} 3.0$ and then switched back to $\mathrm{pH} 7.0$ medium for different time intervals before exposure to 80 $\mathrm{mM}$ acetic acid and cell viability assessed as usual. Yeast cells retained full acetic acid resistance up to $60 \mathrm{~min}$ after switch to neutral medium, whereas $90 \mathrm{~min}$ after reversal of YPD pH from 3.0 to 7.0, cells treated with acetic acid lost about $50 \%$ viability. Thus, pre-incubation in culture medium, set at $\mathrm{pH} 3.0$ with a strong acid, prevents acetic acidtriggered death in exponentially growing yeast cells and the developed resistance is partially reversed after cell incubation for $90 \mathrm{~min}$ in YPD $\mathrm{pH} 7.0$ prior to acetic acid challenge.

To investigate the molecular mechanism by which yeast cells develop resistance to lethal doses of acetic acid after 


\section{A}
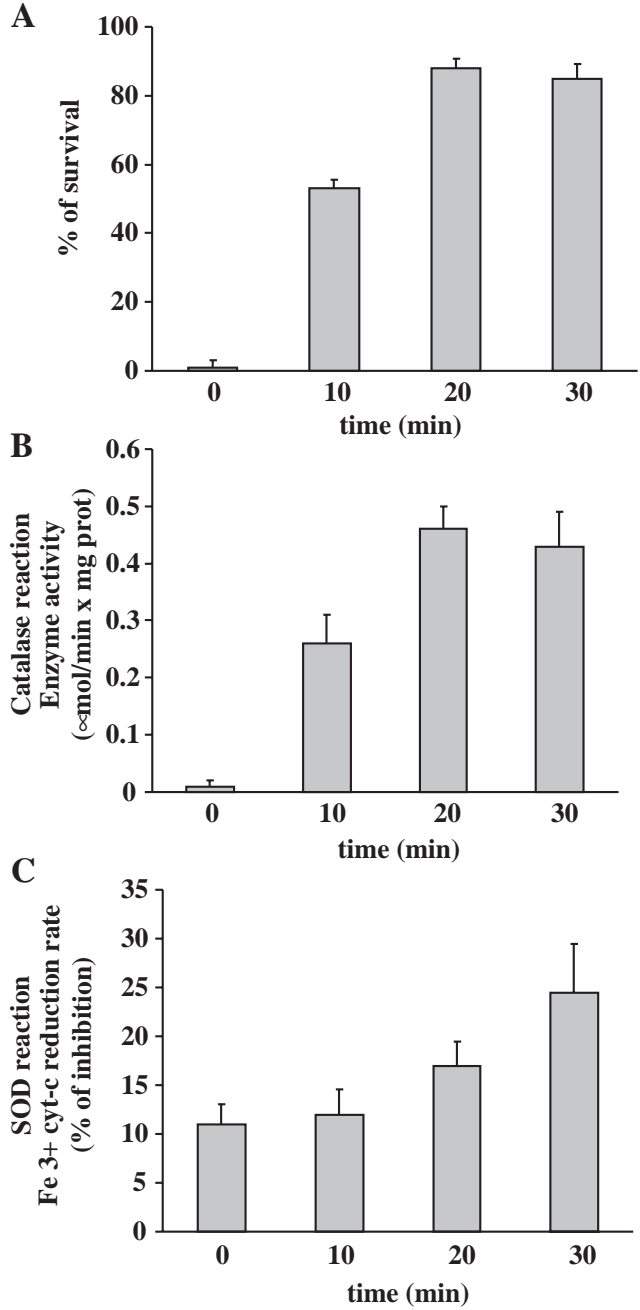

Fig. 3. Effect of extracellular acidification on cell protection from acetic acid-mediated death and on intracellular catalase and superoxide dismutase activities. (A) Cells, grown in YPD medium $\mathrm{pH} 7.0$ up to exponential phase, were incubated in YPD medium $\mathrm{pH} 3.0$ for the indicated times and cell viability was analyzed after $200 \mathrm{~min}$ exposure to acetic acid by cfu counting. Cell survival $(100 \%)$ corresponds to cfu at time zero. Alternatively (B) catalase and (C) SOD activities were determined, as described in Materials and methods, in cells incubated in acidic medium for the indicated times. Mean values of three experiments and standard deviations are reported.

pre-acidification, we measured catalase activity in cells grown in YPD pH 7.0 up to mid-log phase and then incubated for different times in $\mathrm{pH} 3.0$ culture medium. Virtually no catalase activity was measured in exponentialphase cells grown in YPD $\mathrm{pH}$ 7.0. Ten minutes after switching medium $\mathrm{pH}$ to 3.0 , intracellular catalase activity was $0.26 \mu \mathrm{mol} / \mathrm{min} \times \mathrm{mg}$ prot and reached $0.46 \mu \mathrm{mol} /$ $\min \times \mathrm{mg}$ prot after 20 and $30 \mathrm{~min}$ at $\mathrm{pH} 3.0$ (Fig. 3B).

Total SOD activity was also determined in a coupled assay in which the percent inhibition of $\mathrm{Fe}^{3+}$-cytochrome $\mathrm{c}$ reduction rate by superoxide generated by xanthine/xanthine oxidase system was measured. Intracellular SOD activity slightly increased from a value corresponding to $13-15 \%$ inhibition of $\mathrm{Fe}^{3+}$-cytochrome c reduction rate when cells grown in YPD $\mathrm{pH} 7.0$ were incubated for $10 \mathrm{~min}$ in YPD $\mathrm{pH} 3.0$, respectively. An increase of $100 \%$ in $\mathrm{Fe}^{3+}$ cytochrome c reduction rate was measured after $30 \mathrm{~min}$ in acidic medium with respect to cells at $\mathrm{pH} 7.0$ (Fig. 3C).

It is apparent that the increase in catalase and SOD activity mirrors the increase in acetic acid cell death protection in yeast cells incubated in YPD 3.0 before acetic acid treatment (cfr. Fig. 3A, B and C), suggesting that oxidative stress could be a major event in acetic acidtriggered cell death.

\subsection{Catalase activity is specifically increased in cells protected from acetic acid-induced cell death after pre-} incubation in YPD pH 3.0

In order to investigate whether and how oxidative stress could be a critical step in acetic acid-mediated cell death, which is prevented by pre-incubation in YPD pH 3.0, we measured catalase and SOD activity either in cells preincubated for $30 \mathrm{~min}$ in acidic medium and then exposed to acetic acid or in cells directly exposed to acetic acid. Virtually no catalase activity was measured up to $60 \mathrm{~min}$ in yeast cells committed to death after direct exposure to acetic acid (Fig. 4A). In cells pre-incubated for $30 \mathrm{~min}$ in YPD pH
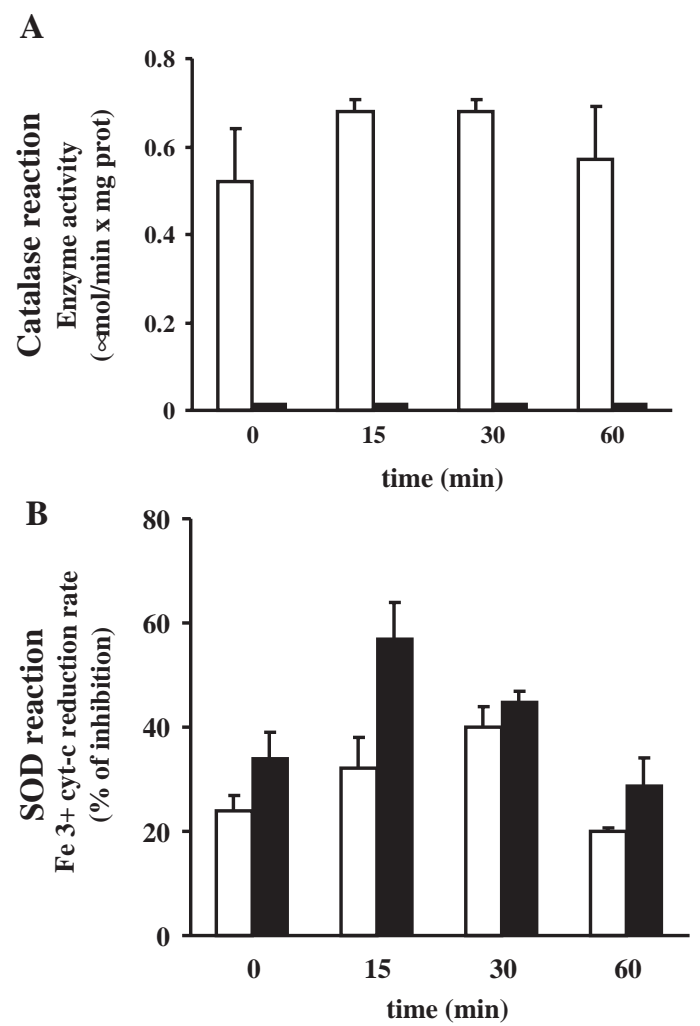

Fig. 4. Catalase and superoxide dismutase activities in dying or protected cells after acetic acid treatment. (A) Catalase and (B) SOD activities were determined in exponential-phase cells exposed to $80 \mathrm{mM}$ acetic acid for the indicated times with (white bars) or without (black bars) pre-incubation in medium YPD pH 3.0 for $30 \mathrm{~min}$. Means of three experiments and standard deviations are reported. 
3.0 catalase activity was drastically increased to about 0.5 $0.6 \mu \mathrm{mol} / \mathrm{min} \times \mathrm{mg}$ prot with respect to the case in which cells were maintained at $\mathrm{pH} 7.0$ prior to acetic acid exposure and the activity remained virtually constant up to $60 \mathrm{~min}$ after exposure to acetic acid (Figs. 3B and 4A).

SOD activity was then determined as above. When yeast cells were shifted from $\mathrm{pH} 7.0$ to 3.0 medium containing 80 $\mathrm{mM}$ acetic acid, SOD activity changed from a value corresponding to $12-34 \%$ inhibition of $\mathrm{Fe}^{3+}$-cytochrome $\mathrm{c}$ reduction rate (cfr Figs. $3 \mathrm{C}$ and $4 \mathrm{~B}$ ), respectively. $\mathrm{Fe}^{3+}$ cytochrome c reduction rate was maximum $(57 \%) 15 \mathrm{~min}$ after acetic acid challenge, corresponding to more than $80 \%$ cell viability (cfr Figs. 1 and 4), and decreased after $60 \mathrm{~min}$ acetic acid treatment to the same level found at the time of death induction (Fig. 4B). In cells protected by preacidification, ferri-cytochrome $\mathrm{c}$ reduction rate inhibition was $25-30 \%$ during $60 \mathrm{~min}$ acetic acid exposure (Fig. 4B). Thus, catalase activity is specifically increased in cells protected from acetic acid-mediated cell death up to $60 \mathrm{~min}$ after acetic acid addition.

\section{Discussion}

A challenge to the yeast field is the continued development of rigorous morphological and biochemical criteria that confidently distinguish chaotic necrotic deaths from more orderly genetic programs of apoptotic-like cell deaths (Goldfarb and Scheffers, 2004). In this paper we propose that $80 \mathrm{mM}$ acetic acid-induced programmed cell death is an adequate experimental set up to further investigate the different molecular events, such as bioenergetical processes and related gene expression regulation, leading to yeast cell demise.

When exposed to sub-lethal extracellular concentration of a strong acid ( $\mathrm{pH} 3.0)$, yeast cells were shown to develop an adaptive response to lethal concentration of acetic acid, and to gain increasing degree of protection from acetic acidmediated cell death, becoming fully resistant to acetic acid challenge after 30 min low $\mathrm{pH}$ medium incubation.

After acetic acid treatment, cells pre-incubated in low $\mathrm{pH}$ medium were not committed to death and high intracellular levels of both catalase and SOD activities were found. On the other hand, in non-adapted cells undergoing acetic acidmediated death, no catalase activity was detected, whereas intracellular SOD activity was found at levels similar to those found in adapted cells, with the only exception of a maximum activity reached in non-adapted dying cells after 15 min acetic acid exposure (Fig. 4A and B). The activity of these enzymes could allow the cells to cope with ROS production under acetic acid-mediated cell death (Ludovico et al., 2002).

The ability of yeast cells to grow at high external hydrogen ion concentration (Fig. 1) reflects their capacity to maintain control over their internal $\mathrm{pH}$ by excluding hydrogen ions (Carmelo et al., 1996, 1997). Increased expression of the cytosolic form of catalase, catalase $\mathrm{T}$, through stress response element has been demonstrated in yeast cells grown in low $\mathrm{pH}$ media when $\mathrm{HCl}$ was used as an acidulant (Schuller et al., 1994; Moskvina et al., 1998). In this context our results give first evidence that extracellular acidification with a strong acid causes an increase in SOD activity as well. This might be consistent with the presence of STRE elements in SOD2 promoter (FlatteryO'Brien et al., 1997). However, the mechanism of catalase and SOD activity induction caused by extracellular medium acidification with a strong acid needs further investigation.

A growing number of evidences suggest that reactive oxygen species may be considered as key signaling molecules in living cells. The involvement of ROS in lipid, protein and nucleic acid oxidative damage and as second messengers in the induction of numerous cellular processes has been demonstrated (Halliwell and Gutteridge, 1990; Khan and Wilson, 1995). The basis of this theory is that ROS are produced as a normal by-product of aerobic life and that the accumulation of oxidative damage due to ROS induces fundamental changes responsible for aging and/or death. Approximately $90 \%$ of the oxygen consumed within a eukaryote is used in mitochondrial respiration. Consequently, ROS production within any given cell is essentially dependent on mitochondrial function and on the level of antioxidant defences. Mitochondria has been implicated as a major source of ROS mainly in processes leading to apoptosis (Moldovan and Moldovan, 2004).

Although we cannot exclude a role of other systems, such as heat shock proteins, in protection of yeast against oxidative damage (Carmelo and Sa-Correia, 1997; Krawiec et al., 2000; Cabiscol et al., 2002), the specific increase in catalase activity found in yeast cells exposed to an environment causing full protection from acetic acidmediated cell death, strongly suggests that oxidative stress could be a critical step in acetic acid-induced death signaling in yeast. In particular, these results suggest that $\mathrm{H}_{2} \mathrm{O}_{2}$, rather than superoxide, detoxification may have a major role in preventing yeast cell death in response to acetic acid.

Further investigations on the source and amount of ROS produced as well as antioxidant gene expression regulation will shed light on the precise role of oxidative stress in acetic acid-mediated yeast cell death.

\section{Acknowledgements}

This work was financed by MIUR-Contributi straordinari di ricerca/aree obiettivo 1 to E. M.

\section{References}

Adams, J.M., 2003. Ways of dying: multiple pathways to apoptosis. Genes Dev. 17, 2481-2495.

Ameisen, J.C., 1996. The origin of programmed cell death. Science 272, $1278-1279$. 
Butow, R.A., Avadhani, N.G., 2004. Mitochondrial signaling: the retrograde response. Mol. Cell 14, 1-15.

Cabiscol, E., Belli, G., Tamarit, J., Echave, P., Herrero, E., Ros, J., 2002. Mitochondrial Hsp60, resistance to oxidative stress, and the labile iron pool are closely connected in Saccharomyces cerevisiae. J. Biol. Chem. 277, 44531-44538.

Carmelo, V., Sa-Correia, I., 1997. HySP26 gene transcription is strongly induced during Saccharomyces cerevisiae growth at low pH. FEMS Microbiol. Lett. 149, 85-88.

Carmelo, V., Bogaerts, P., Sa-Correia, I., 1996. Activity of plasma membrane H+-ATPase and expression of PMA1 and PMA2 genes in Saccharomyces cerevisiae cells grown at optimal and low $\mathrm{pH}$. Arch. Microbiol. 166, 315-320.

Carmelo, V., Santos, H., Sa-Correia, I., 1997. Effect of extracellular acidification on the activity of plasma membrane ATPase and on the cytosolic and vacuolar $\mathrm{pH}$ of Saccharomyces cerevisiae. Biochim. Biophys. Acta 1325, 63-70.

Evans, M.V., Turton, H.E., Grant, C.M., Dawes, I.W., 1998. Toxicity of linoleic acid hydroperoxide to Saccharomyces cerevisiae: involvement of a respiration-related process for maximal sensitivity and adaptive response. J. Bacteriol. 180, 483-490.

Flattery-O'Brien, J.A., Grant, C.M., Dawes, I.W., 1997. Stationary-phase regulation of the Saccharomyces cerevisiae SOD2 gene is dependent on additive effects of HAP2/3/4/5- and STRE-binding elements. Mol. Microbiol. 23, 303-312.

Flohe, L., Otting, F., 1984. Superoxide dismutase assays. Methods Enzymol. 105, 93-104.

Goldfarb, D., Scheffers, L., 2004. Thematic issue “Apoptosis-like cell death programs in yeasts". FEMS Yeast Res. 5, 99-100.

Halliwell, B., Gutteridge, J.M., 1990. Role of free radicals and catalytic metal ions in human disease: an overview. Methods Enzymol. 186, $1-85$.

Hengartner, M.O., 2000. The biochemistry of apoptosis. Nature 407, $770-776$.

Khan, A.U., Wilson, T., 1995. Reactive oxygen species as cellular messengers. Chem. Biol. 2, 437-445.

Krawiec, Z., Bilinski, T., Schuller, C., Ruis, H., 2000. Reactive oxygen species as second messengers? Induction of the expression of yeast catalase $\mathrm{T}$ gene by heat and hyperosmotic stress does not require oxygen. Acta Biochim. Pol. 47, 201-207.
Lewis, K., 2000. Programmed death in bacteria. Microbiol. Mol. Biol. Rev. 64, 503-514.

Luck, H., 1954. Quantitative determination of catalase activity of biological material. Enzymologia 17, 31-40.

Ludovico, P., Sousa, M.J., Silva, M.T., Leao, C., Corte-Real, M., 2001. Saccharomyces cerevisiae commits to a programmed cell death process in response to acetic acid. Microbiology 147, 2409-2415.

Ludovico, P., Rodrigues, F., Almeida, A., Silva, M.T., Barrientos, A., CorteReal, M., 2002. Cytochrome c release and mitochondria involvement in programmed cell death induced by acetic acid in Saccharomyces cerevisiae. Mol. Biol. Cell 13, 2598-2606.

Madeo, F., Herker, E., Wissing, S., Jungwirth, H., Eisenberg, T., Frohlich, K.U., 2004. Apoptosis in yeast. Curr. Opin. Microbiol. 7, 655-660.

Matsuyama, S., Nouraini, S., Reed, J.C., 1999. Yeast as a tool for apoptosis research. Curr. Opin. Microbiol. 2, 618-623.

Moldovan, L., Moldovan, N.I., 2004. Oxygen free radicals and redox biology of organelles. Histochem. Cell Biol. 122, 395-412.

Moskvina, E., Schuller, C., Maurer, C.T., Mager, W.H., Ruis, H., 1998. A search in the genome of Saccharomyces cerevisiae for genes regulated via stress response elements. Yeast 14, 1041-1050.

Newmeyer, D.D., Ferguson-Miller, S., 2003. Mitochondria: releasing power for life and unleashing the machineries of death. Cell 112, 481-490.

Piper, P., Calderon, C.O., Hatzixanthis, K., Mollapour, M., 2001. Weak acid adaptation: the stress response that confers yeasts with resistance to organic acid food preservatives. Microbiology 147, 2635-2642.

Schuller, C., Brewster, J.L., Alexander, M.R., Gustin, M.C., Ruis, H., 1994. The HOG pathway controls osmotic regulation of transcription via the stress response element (STRE) of the Saccharomyces cerevisiae CTT1 gene. EMBO J. 13, 4382-4389.

Schuller, C., et al., 2004. Global phenotypic analysis and transcriptional profiling defines the weak acid stress response regulon in Saccharomyces cerevisiae. Mol. Biol. Cell 15, 706-720.

Skulachev, V.P., 1999. Phenoptosis: programmed death of an organism. Biochemistry (Mosc.) 64, 1418-1426.

Skulachev, V.P., 2002. Programmed death in yeast as adaptation? FEBS Lett. 528, 23-26.

Wang, X., 2001. The expanding role of mitochondria in apoptosis. Genes Dev. 15, 2922-2933.

Wyllie, A.H., Kerr, J.F., Currie, A.R., 1980. Cell death: the significance of apoptosis. Int. Rev. Cyt. 68, 251-306. 